\title{
Virus-triggered autophagy in viral hepatitis - possible novel strategies for drug development
}

\author{
S.M. Alavian, S.R. Ande, K.M. Coombs, B. Yeganeh, Padideh Davoodpour, M. Hashemi, \\ Marek Jan Los and S. Ghavami
}

\section{Linköping University Post Print}

N.B.: When citing this work, cite the original article.

This is the authors' version of the following article:

S.M. Alavian, S.R. Ande, K.M. Coombs, B. Yeganeh, Padideh Davoodpour, M. Hashemi, Marek Jan Los and S. Ghavami, Virus-triggered autophagy in viral hepatitis - possible novel strategies for drug development, 2011, Journal of Viral Hepatitis, (18), 12, 821-830.

which has been published in final form at:

http://dx.doi.org/10.1111/j.1365-2893.2011.01530.x

Copyright: Blackwell Publishing http://www.blackwellpublishing.com/

Postprint available at: Linköping University Electronic Press http://urn.kb.se/resolve?urn=urn:nbn:se:liu:diva-73733 


\title{
Virus-Triggered Autophagy in Viral Hepatitis - possible novel strategies for drug development.
}

\author{
Running title: Role of autophagy in $\mathrm{HBV}$ and $\mathrm{HCV}$
}

\author{
Seyed Moayed Alavian', Sudharsana R. Ande ${ }^{2}$, Kevin M. Coombs ${ }^{3}$, Behzad \\ Yeganeh $^{4,5}$, Padideh Davoodpour ${ }^{6}$, Mohammad Hashemi ${ }^{7,8}$, Marek Los ${ }^{9,10^{*}}$, Saeid \\ Ghavami $^{4,5^{*}}$ \\ ${ }^{1}$ Baqiyatallah Research Center for Gastroenterology and Liver Diseases, Tehran, Iran; \\ ${ }^{2}$ Department of Internal Medicine, University of Manitoba, Winnipeg, MB, Canada; \\ ${ }^{3}$ Department of Medical Microbiology, Faculty of Medicine, University of Manitoba, Winnipeg, MB, \\ Canada; \\ ${ }^{4}$ Department of Physiology, University of Manitoba, Winnipeg, MB, Canada; \\ ${ }^{5}$ Biology of Breathing Group, Manitoba Institute of Child Health, Winnipeg, MB, Canada. \\ ${ }^{6}$ Division of Cardiovascular Medicine \& Integrative Regenerative Med. Center (IGEN), Department of \\ Medical and Health Sciences, Linköping University, Linköping, Sweden; \\ ${ }^{7}$ Department of Clinical Biochemistry, School of Medicine, Zahedan University of Medical Sceince, \\ Zahedan, Iran; \\ ${ }^{8}$ Cellular and Molecular Research Center, Zahedan University of Medical Sceince, Zahedan, Iran; \\ ${ }^{9}$ Dept. Clinical \& Experimental Medicine \& Integrative Regenerative Med. Center (IGEN), Linköping \\ University, Sweden; \\ ${ }^{10}$ BioApplications Enterprises, Winnipeg, MB, Canada;

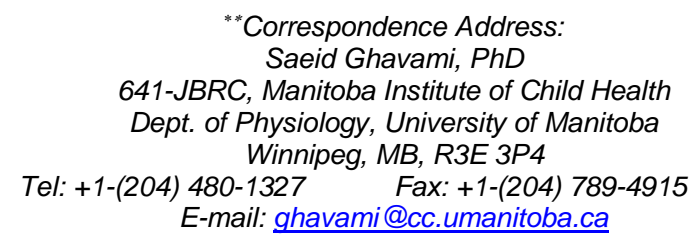

Keywords: autophagy, HBV, HCV, virus replication, therapeutic application

Abbreviation: Hepatitis B virus; HBV, hepatitis $C$ virus; HCV, hepatocellular carcinoma; HCC, World Health Organization; WHO, hepatitis B e Antigen; HBe Ag , interleukin 28B; IL28B, hepatitis B surface antigen; HBsAg, covalently closed circular; ccc, endoplasmic reticulum; ER, direct repeat; DR, non-structural proteins; NSP, internal ribosome entry site; IRES, RNA-dependent RNA polymerase; RdRp, chaperonemediated autophagy; CMA, lysosome-associated membrane protein type 2A; LAMP2A, autophagy-related genes; Atgs, mammalian target of rapamycin; mTOR, phosphatidylinositol 3-kinase; PI3K, AMP-activated kinase; AMPK, c-Jun NH2-terminal kinase-1; JNK1, microtubule associated protein 1 light chain 3; LC3, Coxsackievirus B3; CVB3, small surface proteins; SHBs, HBV X protein; HBx, Unfolded Protien Response; UPR, pancreatic ER kinase like ER kinase; PERK, activating trascription factor 6; ATF6, inositol requiring enzyme 1; IRE1, C/EBP homologous protein; CHOP 


\begin{abstract}
Autophagy is a very tightly regulated process that is important in many cellular processes including development, differentiation, survival, and homeostasis. The importance of this process has already been proven in numerous common diseases such as cancer and neurodegenerative disorders. Emerging data indicate that autophagy plays an important role in some liver disease including liver injury induced by ischemia reperfusion and alpha-1 antitrypsin $Z$ allele dependent liver disease. Autophagy may also occur in viral infection, and it may play a crucial role in antimicrobial host defense against pathogens, while supporting cellular homeostasis processes. Here the latest findings on the role of autophagy in viral hepatitis B and C infection, which are both serious health threats, will be reviewed.
\end{abstract}




\section{Introduction}

Chronic viral hepatitis infection represents a major public health problem worldwide (1, 2). It can be caused by several viruses, the most widespread being hepatitis $B$ and $C$ viruses (HBV and HCV, respectively) (3). Hepatitis B and C may cause chronic liver infection that can lead to liver fibrosis and ultimately develop to liver cirrhosis and primary liver cancer. Current understanding of these infections has been advanced by studies of the mechanisms of liver fibrosis. Fibrosis was considered a progressive linear event but clinical evidence now suggests that fibrosis progression does not always have a fixed speed, but instead can have slower or rapid phases(4). We have recently shown a direct link between autophagy and fibrosis in different systems (Ghavami and Halayko unpublished data) including in different viral infections (5-7). Here we focus on and review the importance of autophagy in viral hepatitis $B$ and $C$ infection and discuss some future possible targets for viral hepatitis $B$ and $C$ therapeutic strategies.

\section{Epidemiology of $\mathrm{HBV}$ and $\mathrm{HCV}$ in the world}

At the beginning of the third millennium, HBV infection poses a great burden on health systems around the world $(8,9), 350-400$ million suffering from this infection (10). It has been identified as one of the most important causes of liver failure and hepatocellular carcinoma (HCC) (11). HBV can be transmitted parenterally by percutaneous and mucous membrane exposures to infected blood, sexual contact or perinatal exposure $(12,13)$. 
The World Health Organization (WHO) has compared hepatitis $\mathrm{C}$ virus (HCV) to a "viral time bomb" and estimates that about 180 million people (around 3\% of the world's population) are infected with $\mathrm{HCV}, 130$ million of whom are chronic carriers at risk of developing liver cirrhosis and liver cancer (14). The main risk factors for HCV infection are blood and blood product transfusion, intravenous drug use, unsafe injections, tattooing and poor instrument disinfection by barbers, and rarely sexual contact. Haemodialysis, thalassaemia and haemophilia patients are at higher risk of HCV infection $(9,15,16)$.

\section{Natural history and progression of HBV and HCV to cirrhosis and HCC}

Hepatitis B virus infection has two presentations; acute, which occurs less than 6 months after acquiring the infection and is symptomatic, and the chronic phase of infection, which occurs more than 6 months after initial infection. HBV infection can be divided temporally into different stages after initial acquisition. The first stage is characterized as immune-tolerance (17). In the second phase, the immune response becomes active and leads to cytokine release and cell lysis and an inflammatory infiltrate accumulates (10). The progression of HBV infection and the evolution of the various phases depends on host genetic factors and molecular characteristics of HBV such as genotype and presence of viral mutations (18).

The natural history of HCV infection is totally different from HBV infection. Approximately $20 \%$ of individuals spontaneously clear the infection. Again there are viral and host factors that determine HCV clearance or persistence(19). Host genetic variation has been shown to contribute to the heterogeneity in HCV clearance and rate 
of response to antiviral therapy $(20,21)$. About $30 \%$ of individuals with persistent infection develop chronic liver disease, such as cirrhosis and hepatocellular carcinoma (22).

\section{$\mathrm{HBV}$ and HCV classification and structure}

\section{$H B V$}

\section{Classification and Structure}

HBV belongs to the Hepadnaviridae family. These viruses are characterized by having a partial double-stranded DNA genome, with numerous overlapping genes in multiple reading frames, which is copied through an RNA intermediate by a reverse transcriptase enzyme. HBV infects primarily hepatocytes. For more complete reviews, see (23-25). The HBV, also known as the Dane particle, is approximately $45 \mathrm{~nm}$ in diameter. The HBV genome is a circular DNA molecule of approximately 3200 nucleotides (Fig. 1A) that encodes 3 different-sized envelope proteins (HBsAg) as well as several other structural and non-structural proteins (Fig. 1B, Table 1). At least one of the non-structural proteins $(\mathrm{HBx})$ has been suggested to have a role in autophagy. Tang and colleagues found that HBx was involved in up-regulation of beclin-1 expression during starvation-induced autophagy (26). Sir and colleagues demonstrated that HBV infection induced early autophagy in the absence of autophagic protein degradation, that autophagy enhanced HBV replication and that this was mediated by interaction between $\mathrm{HBx}$ and $\mathrm{PI} 3 \mathrm{KC} 3$ to enhance the latter's activity (27). Other recent work by $\mathrm{Li}$ and colleagues has confirmed that HBV induces autophagy and that this induction aids virus replication. However, Li et al demonstrated, using a different vector construct and 
different virus types, that the smallest structural envelope protein (SHBs) also has roles in autophagy by promoting endoplasmic reticulum stress and virion envelopment (28).

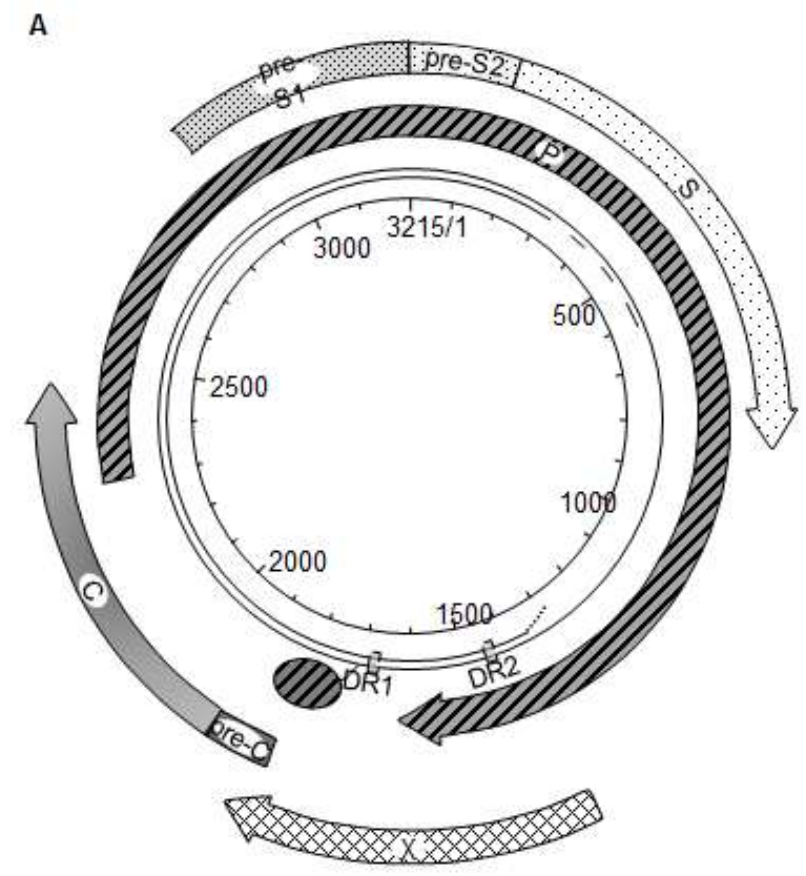

B

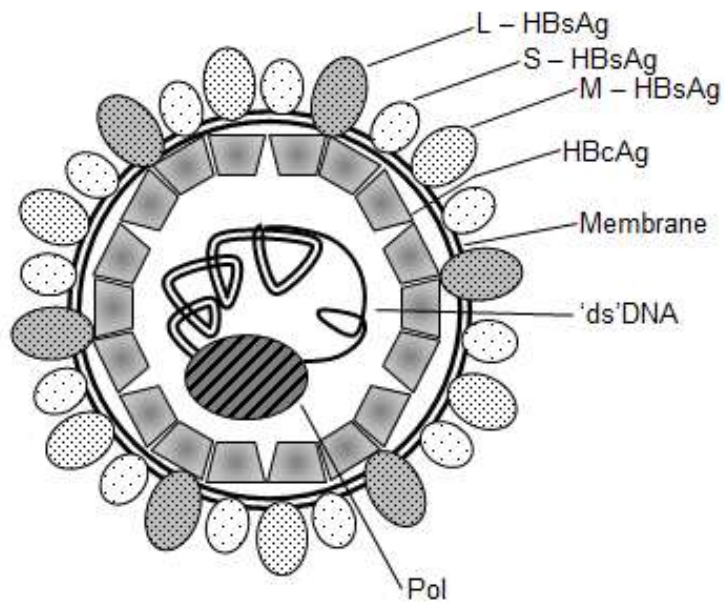

Figure 1. (A). Map of the HBV genome. The viral genome consists of a full-length circular (-) sense DNA strand complexed with a shorter, partial (+) sense DNA strand. The shorter $(+)$ sense strand, of varying length, is indicated by the wide dashes between map positions $\sim 300-600$ nt. The $(+)$ sense strand also contains a short $\sim 170$ nt oligoribonucleotide tail, indicated by the dotted line at map position $\sim 1300$. The viral polymerase protein (indicated by the hatched oval) binds to the 5' end of the (-) sense strand. The genome contains short direct repeats (DR1, DR2). Open reading frames (orf) are indicated by various arrows. Different reading frames are indicated by arrow distance from center. Precise locations of each protein, denoted by different fill patterns, are indicated in Table 1 for the HB056 strain; GenBank \# HM011465.

(B) Cartoon of HBV virion. The viral genome (innermost single / double line) and genome-bound polymerase, is encased in an icosahedral shell composed of HBcAg. This core is surrounded by a host-derived lipid bilayer (double circular line) in which are embedded the 3 different sizes of small (S), medium (M), and large (L) HBsAg.

\section{$\mathrm{HCV}$}

\section{Classification and Structure}

HCV belongs to the Hepacivirus genus in the Flaviviridae family. Flaviviruses have single-stranded, plus-sense (+) RNA genomes. The $\sim 9.6 \mathrm{~kb}$ genome acts directly as 
mRNA and all viral structural proteins as well as six non-structural proteins (NSP) are produced from a 3000aa polyprotein precursor by viral and cellular proteases (Fig. 2A). The genome is encased by a nucleocapsid made from multiple copies of a single capsid (C) protein, which is surrounded in turn by a host-derived lipid envelope (Fig. 2B), that contains two viral-encoded proteins, called E1 and E2 (Table 2). Basic residues in the amino terminal portion of $C$ protein are essential for genomic encapsidation (29). The precise numbers of $C$ proteins, and native virion nucleocapsid dimensions, are not yet known. For more complete reviews, see $(24,30,31)$. ER stress and induction of the host cell unfolded protein response (UPR) have been known to be involved in HCV-mediated autophagy (32). Similar responses were found by Asselah and colleagues to occur in HCV-infected liver biopsies (33). Guevin and colleagues reported that the viral non-structural protein NSP5B, the viral RNA-dependent RNA polymerase (Table 2), interacts with host proteins required for autophagy induction (6), and Ke and colleagues presented data that suggest UPR induction and formation of autophagic vacuoles was induced by HCV replication (34). Thus, as described in more detail in later sections, both HBV and HCV encode proteins that induce autophagy to the virus' benefit.

\section{Over view of autophagy mechanism}

Autophagy (Greek for "self-eating") refers to evolutionary conserved catabolic processes in which cytoplasmic macromolecules and organelles are degraded by lysosomes because they are damaged or they are needed as substrates to maintain energy homeostasis $(35,36)$. Autophagy can be selective or non-selective with respect to the cytoplasmic component being degraded and targeted during this mechanism (37, 

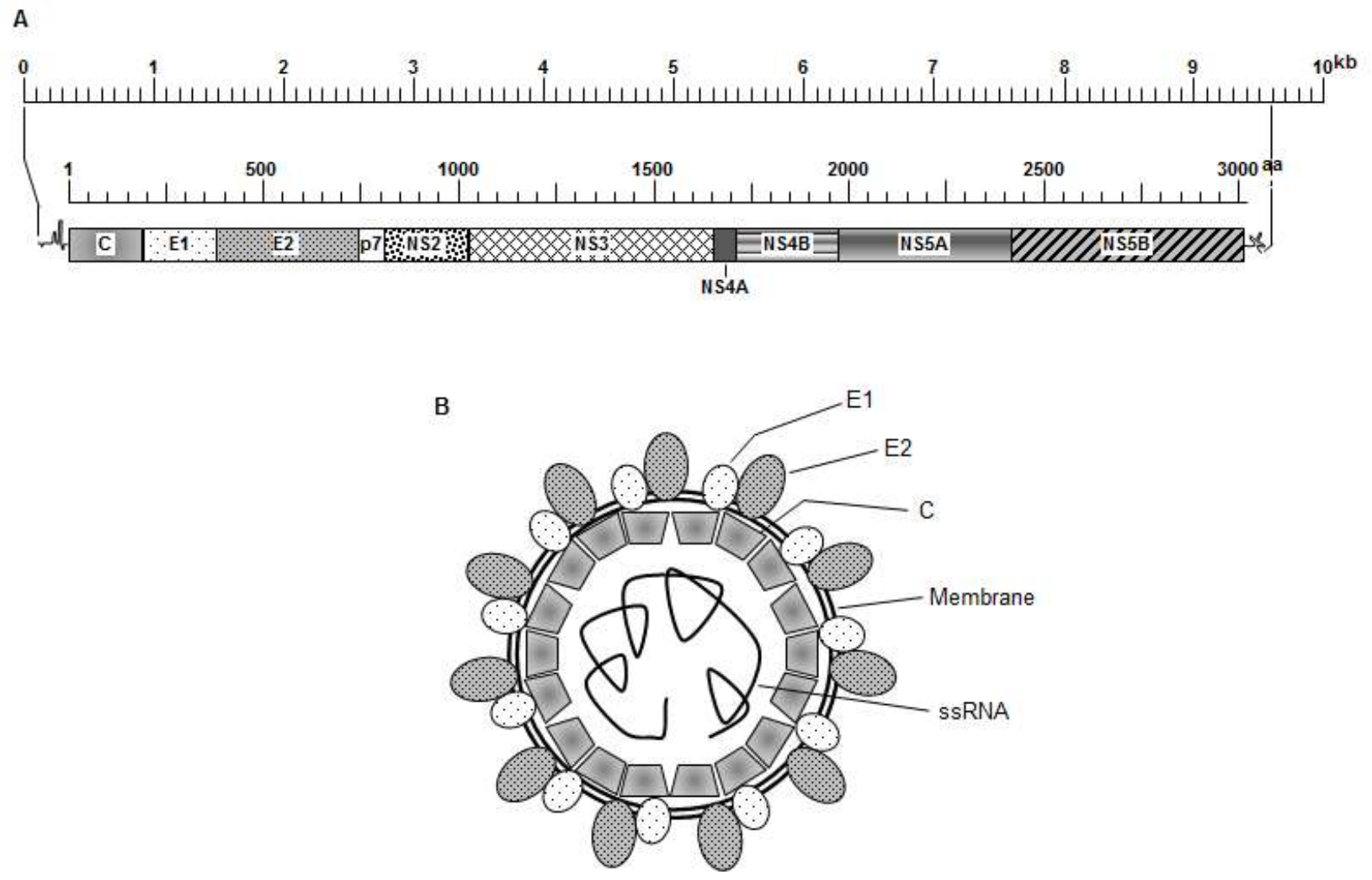

Figure 2. (A) Map of the HCV genome. The viral genome consists of a linear singlestranded $(+)$ sense RNA molecule of $\sim 9600$ nucleotides that encodes for an $\sim 3010$ amino acid long polyprotein. Upper scale line indicates nucleotides; lower scale line denotes amino acids. The 5' and 3' non-translated regions contain nucleotides predicted to fold into various regulatory secondary structures. Precise locations of each protein, released by viral and cellular proteases and denoted by different fill patterns, are indicated in Table 2 for the J4 clone; GenBank \# AF054247.

(B) Cartoon of HCV virion. The viral genome (innermost single line), is encased in an icosahedral shell composed of capsid protein. This nucleocapsid is surrounded by a host-derived lipid bilayer (double circular line) in which are embedded the E1 and E2 envelope proteins.

38). Examples of selective autophagy include mitophagy (degradation of mitochondria), ER-phagy (endoplasmic reticulum), ribophagy (ribosomes), pexophagy (peroxisomes), lipophagy (lipids) and xenophagy (pathogens) (39-44). Autophagy occurs under basal conditions but can also be stimulated by stresses like starvation, various pathologies or by pharmacological agents $(45,46)$. Disturbances in autophagy may play important roles in aging and in various disease conditions involving the liver, cardiac and skeletal 
muscle as well as cancer, neurodegenerative, metabolic, inflammatory and infectious diseases $(36,39,47)$. With respect to infectious disease, some pathogens have evolved mechanisms to escape, inhibit or even exploit autophagy for their own benefit $(36,47)$.

Apart from macro-autophagy, there are at least two other forms of autophagy. One is chaperone-mediated autophagy (CMA) in which specific proteins containing a consensus peptide motif are translocated to the lysosome where binding to the lysosome-associated membrane protein type 2 A (LAMP-2A) receptor is followed by protein internalization and degradation. The other is micro-autophagy in which cytosolic contents are internalized into lysosomes after direct invagination of the lysosomal membrane (35).

In macro-autophagy (commonly, and in this review hereafter, referred to as autophagy), a portion of the cytoplasm becomes engulfed by an isolation membrane known as the phagophore (48). Through not fully understood mechanisms mediated by multiprotein complexes, a double-membrane structure (possibly derived from the ER, plasma membrane or mitochondria) called autophagosome is formed, the ends of which elongate until they fuse around the cargo (Fig. 3) (37, 49). The autophagosome eventually fuses with the lysosome forming an autolysosome after which its contents are degraded by the lysosomal enzymes (50).

In yeast, more than 30 conserved autophagy-related genes (Atg) with several mammalian orthologs have been identified which are involved in the regulation of autophagy. One important pathway involves the mammalian target of rapamycin (mTOR) which negatively regulates a downstream complex of Atg1 (called ULK1 in mammals) Atg13 and FIP200 (39) (Fig. 3). Activation of mTOR by class I 


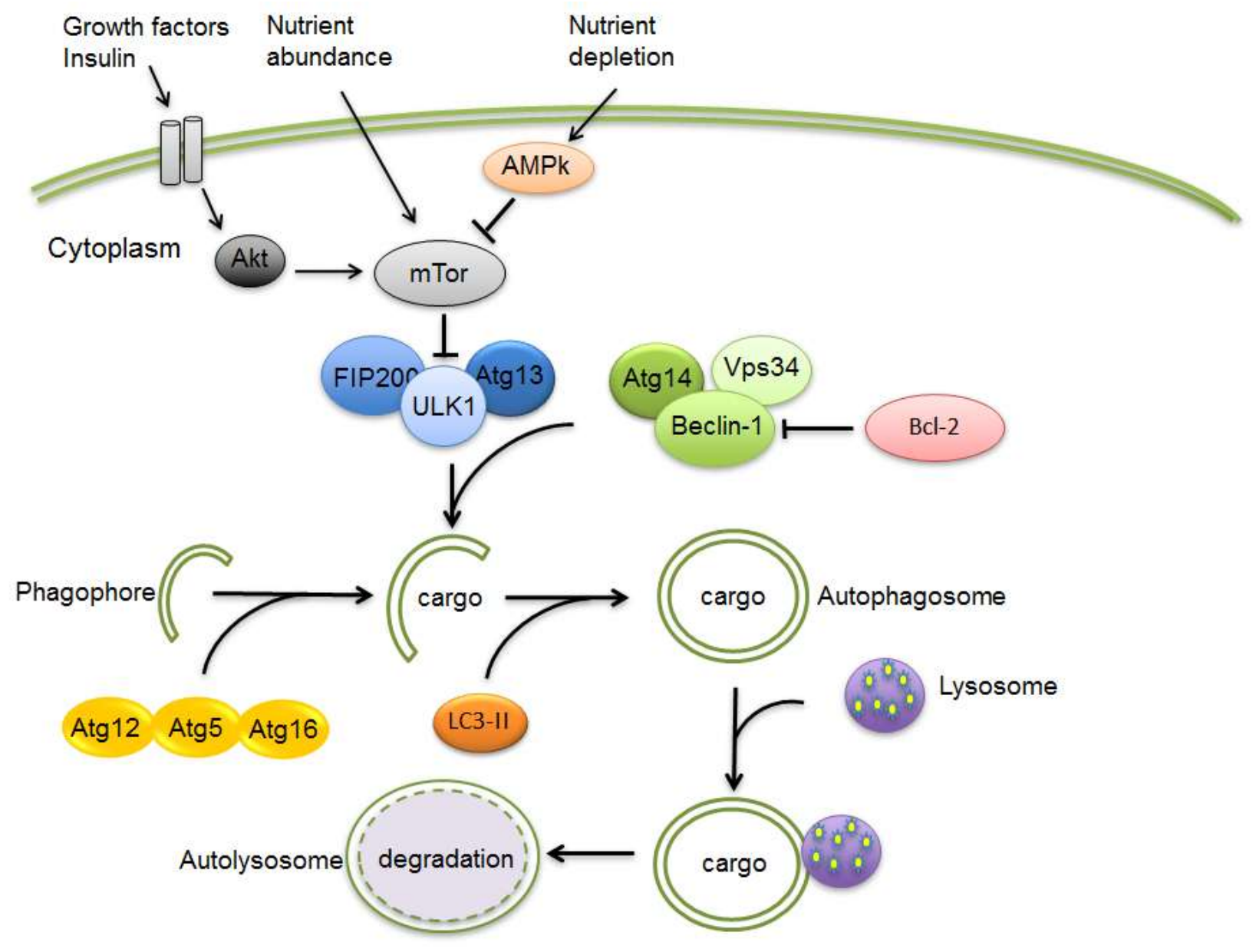

Figure 3. Summary of autophagy machinery in mammalian cells. Growth factors may inhibit autophagy via Akt activation while nutrient depletion induce this process via activation of adenosine mono phosphate protein kinase (AMPK) with subsequent inhibition of mTOR. Bcl-2 plays an important function in inhibiting autophagy by direct interaction with Beclin-1. After activation of the autophagy process, an autophagosome is formed which engulfs the cargo (e.g. damaged organelles). Two ubiquitine-like chain reactions involving Atg12-Atg5-Atg16 formation and LC3 I lipidation are involved in autophagosome double membrane formation. The autophagosome finally fuses with a lysosome forming an autophagolysosome and its content is subsequently digested by lysosomal enzymes.

phosphatidylinositol 3-kinase (PI3K)-induced phosphorylation of Akt in response to insulin or growth factors results in inhibition of autophagy (51). In starvation, activation of AMP-activated kinase (AMPK) conversely inhibits mTOR and induces autophagy. Besides the ULK1 complex, another factor implicated in initiation of autophagosome formation is the class III PI3K Vps34, the activity of which is enhanced by interaction 
with Beclin 1/Atg6 $(51,52)$ (Fig. 3). Binding of Beclin 1 by the anti-apoptotic protein Bcl2 inhibits autophagy (37).

The elongation of pre-autophagosomal structures involves two ubiquitine-like reactions, the first of which results in a complex between Atg12, Atg5 and Atg16 which is essential for the elongation (39). The second is the microtubule-associated protein light chain 3 (LC3)-I (53). Following a reaction involving Atg7 and Atg3, LC3-I is converted to LC3-II, which is targeted to the elongating autophagosomal membrane (39, 53). In contrast to the Atg12-Atg5-Atg16 complex, LC3-II remains bound to it until it has fused with the lysosome forming the autolysosome and LC3-II is commonly used to monitor autophagy $(54,55)$. The contents of the autolysosome are degraded by proteases, lipases, nucleases, and glycosidases. Lysosomal permeases release the breakdown products into the cytosol for use in synthetic and metabolic pathways (56).

\section{Virus and Autophagy}

Many viruses are currently listed in the literature that are shown to induce autophagy. Here we summarize some of the DNA and RNA encoding viruses that induce autopaghy.

\section{DNA Viruses}

Herpes Simplex virus1 (HSV1) and Human Cytomegalovirus virus (HCMV) are DNA encoding viruses that are members of the Herpesviridae family. Recently it was demonstrated that upon infection of human fibroblasts by these two viruses, early induction of autophagy with extensive lipidation of microtubule associated protein 1 light 
chain 3 (LC3) is promoted (57). Another virus called Simian virus 40 that belongs to the family Polyomaviridae also enhances autophagy in HEK cells by inhibiting mTOR, and it is unclear whether autophagy induction by this virus enhances viral yield (58).

\section{RNA Viruses}

Dengue virus, like HCV, belongs to the family Flaviviridae and it induces autophagy in vitro. Autolysomes formed upon Dengue virus infection are associated with helping viral replication and an increase in the viral yield $(7,59)$. Influenza A virus belongs to the family Orthomyxoviridae and its infection increases autophagy and autophagic flux through an unknown mechanism, and an increase in autophagy enhances viral replication and viral yield (59). Polio virus is with a member of the family Picornaviridae. Polio virus infection triggers autophagy with the accumulation of LC3-positive autophagosome-like structures which assist viral replication in a non-lytic manner. An increase in viral replication and viral yields have been associated with the autophagy $(60,61)$. Another virus from the same family is Coxsackievirus B3 (CVB3). CVB3 induces autophagy and also blocks the maturation of autophagosomes by an unknown mechanism. Increase in viral replication and yield of the virus has been reported due to the autophagy induction of this virus (62). Autophagy increased the replication of another Picornaviridae member, Encephalomyocarditis virus (EMCV) in host cells and released the virus particles in the cytoplasm in non-lytic manner. This evidence strongly suggests that autophagy helps in the replication of the ECMV virus (63). 


\section{Importance of autophagy in HBV and HCV infection and pathogenesis}

As previously mentioned, autophagy is a key metabolic process that can eliminate unwanted, damaged and worn out constituents of the cells. However viruses use this process to modulate their replication in host cells. Some of the best examples of such viruses are HBV and HCV. Studying HCV and its role in pathogenesis of hepatitis is vital, and may lead to development of novel drugs that could be used for the treatment of viral hepatitis infected patients. There are reports in the literature that HCV induces autophagy in hepatocytes (5). As was mentioned earlier, during autophagy, double membrane vesicles are formed known as autophagosomes. These autophagosomes fuse with lysosomes to form autolysosomes and degrade their contents. HCV induces incomplete autophagy via unfolded protein response pathway (32). In these experimental studies, authors showed that $\mathrm{HCV}$ prevents the maturation of autophagosomes to autolysosomes so that the contents of the autophagosome are not degraded and HCV can use them for its replication (32). This is one of the ways that HCV could possibly escape from the degradation by the autophagy pathway. HCV may also avoid autophagy by preventing itself from being recognized by autophagy machinery. Immuno-electron microscopy and immunofluoresence results showed that there is no- or rare co-localization of HCV proteins with the autophagic vacuoles (47). Therefore, HCV hides from being recognized by the host cells' defenses. HCV, following its cell entrance, uses the host cell factors to help in its replication. It has been experimentally proven that HCV uses autophagy related proteins such as Beclin 1, Atg4B, Atg5 and Atg12 for the translation of the viral mRNA thereby initiating its replication. Once the replication is initiated, HCV can multiply itself and enhance the 
infection (64). It was reported that the viral non-structural protein NSP5B, the viral RNAdependent RNA polymerase, interacts with host proteins required for autophagy induction (6), and Ke and colleagues presented data that suggest UPR induction and formation of autophagic vacuoles was induced by HCV replication (34). HCV infection activates three main arms in UPR including ATF6, IRE $\alpha$ 1, and PERK, which induces CHOP expression (a UPR-dependent transcriptional factor) (Fig. 5). Knocking down of CHOP or inhibiting each of the UPR arms inhibits autophagy in HCV-infected cells which highlights the importance of UPR in HCV-induced autophagy (65). This evidence emphasizes the role of autophagy-and UPR-related genes in HCV replication. Chloroquine, which is an inhibitor of autophagic proteolysis, also inhibits HCV replication in liver cells (66). Treatment with chloroquine down-regulates HCV replication in a dose dependent manner, indicating that autophagy-proteolysis plays an important role in viral replication. These experimental results highlight the fact that autophagic proteolysis can be a target for the treatment of viral hepatitis. Apart from that, this report suggests that chloroquine can be used as a drug for the treatment of chronic hepatitis $C$ (66). The recent report by Shrivatsava et al demonstrates that the knockdown of autophagy related proteins, Beclin 1 or autophagy related protein 7 (Atg7) in immortalized human hepatocytes infected with HCV, enhances the interferon signaling pathways and induces apoptosis. However, the activation of interferon signaling pathway and apoptosis are absent in infected control immortalized human hepatocytes. These experimental evidences also show that HCV induced autophagy impairs innate immunity (67). 
HBV regulates and "hires" autophagy for its benefit to promote replication. A recent report shows that HBV can enhance the autophagic process in hepatoma cells without promoting the degradation of lysosomes (28). This report also demonstrates by mutational analysis that HBV small surface proteins $(\mathrm{HBsAg})$ are required to induce autophagy. Transfection of $\mathrm{HBsAg}$ is sufficient enough to induce autophagy in hepatoma cells. Autophagy machinery is activated during HBV infection and is responsible for enhancement of HBV replication in the cells (28). Another experimental finding shows that HBV transfected into the hepatoma cells induces an early autophagic response without increasing the autophagic protein degradation (27). This autophagic response enhances viral replication through the binding of $\mathrm{HBV} X$ protein $(\mathrm{HBX})$ to PI3KC3. These experimental studies provide evidence that the autophagy pathway can be used as a target for the treatment of patients with HBV infection $(26,27)$. In the report published by Tang and colleagues (26), HBVx protein when transfected into the hepatocytes, leads to the increased activity of Beclin 1 protein expression, which in turn leads to the enhancement of autophagy. These results certainly provide evidence that HBV can induce autophagy in hepatocytes and thereby using this process for enhancing its replication. In conclusion, the autophagy pathway can be a target for designing drugs that better serve the purpose of patients with HBV infections in the liver. The role of autophagy in HBV infection is summarized in Figure 4.

\section{Conclusion and Future Direction}

Tremendous progress in research on liver pathology in recent years allowed for characterization of diverse forms of hepatitis. Hepatitis is usually induced by infection by 
different pathogens and routes. Recent discoveries suggest several preventive strategies, including vaccines and passive immunization approaches, will be useful

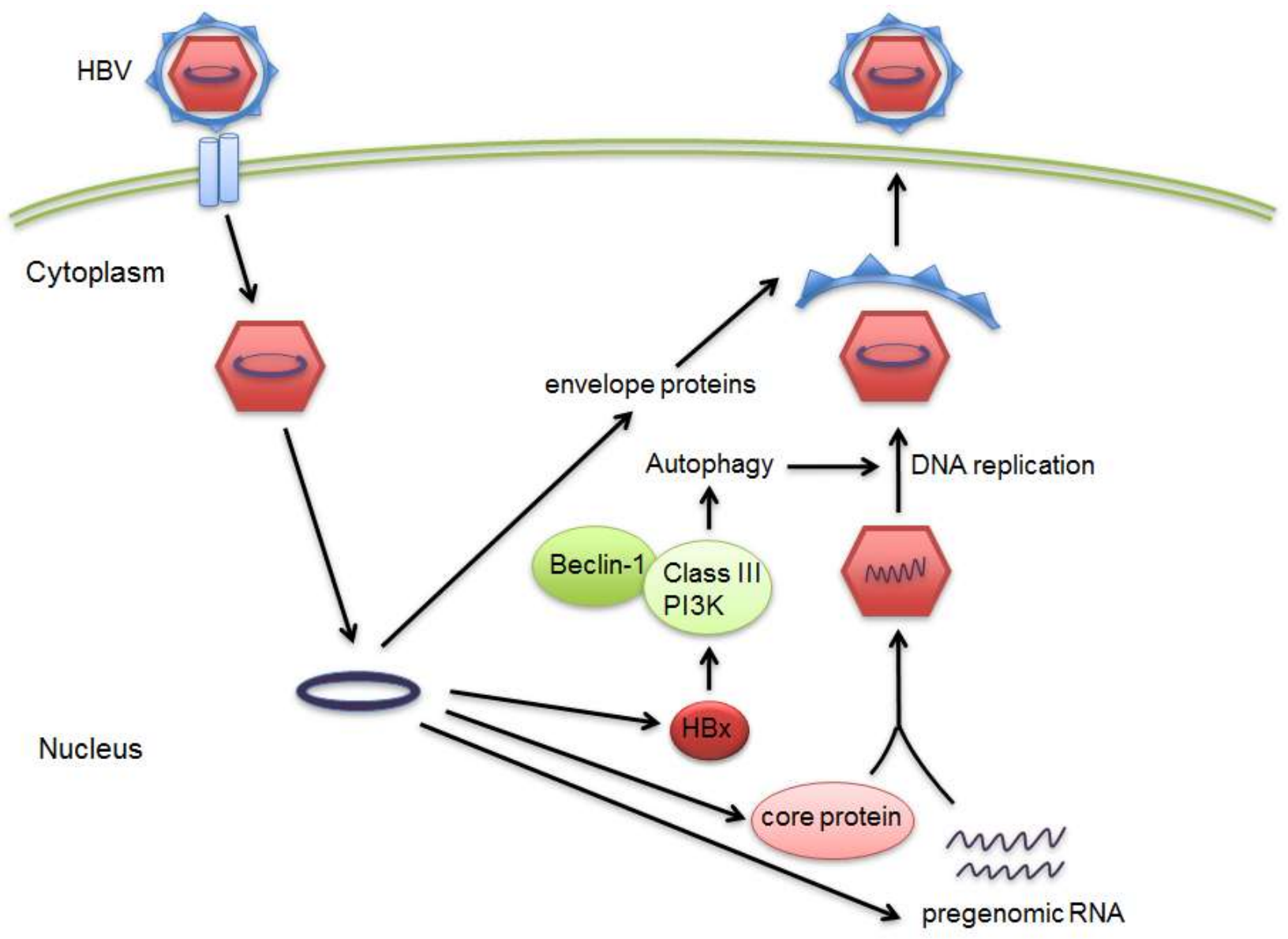

Figure 4. Autophagy involvement in life cycle of HBV. After infection of the cell by HBV, the viral particle moves to the host cell nucleus and the viral RNA particles are made and induce viral protein synthesis. Later the HBx protein is synthesized by HBx RNA which has been already made by host cells. HBx activated PI3K class III-induced autophagy via up-regulation of Beclin-1 synthesis. Autophagy later helps and activate viral DNA replication. 


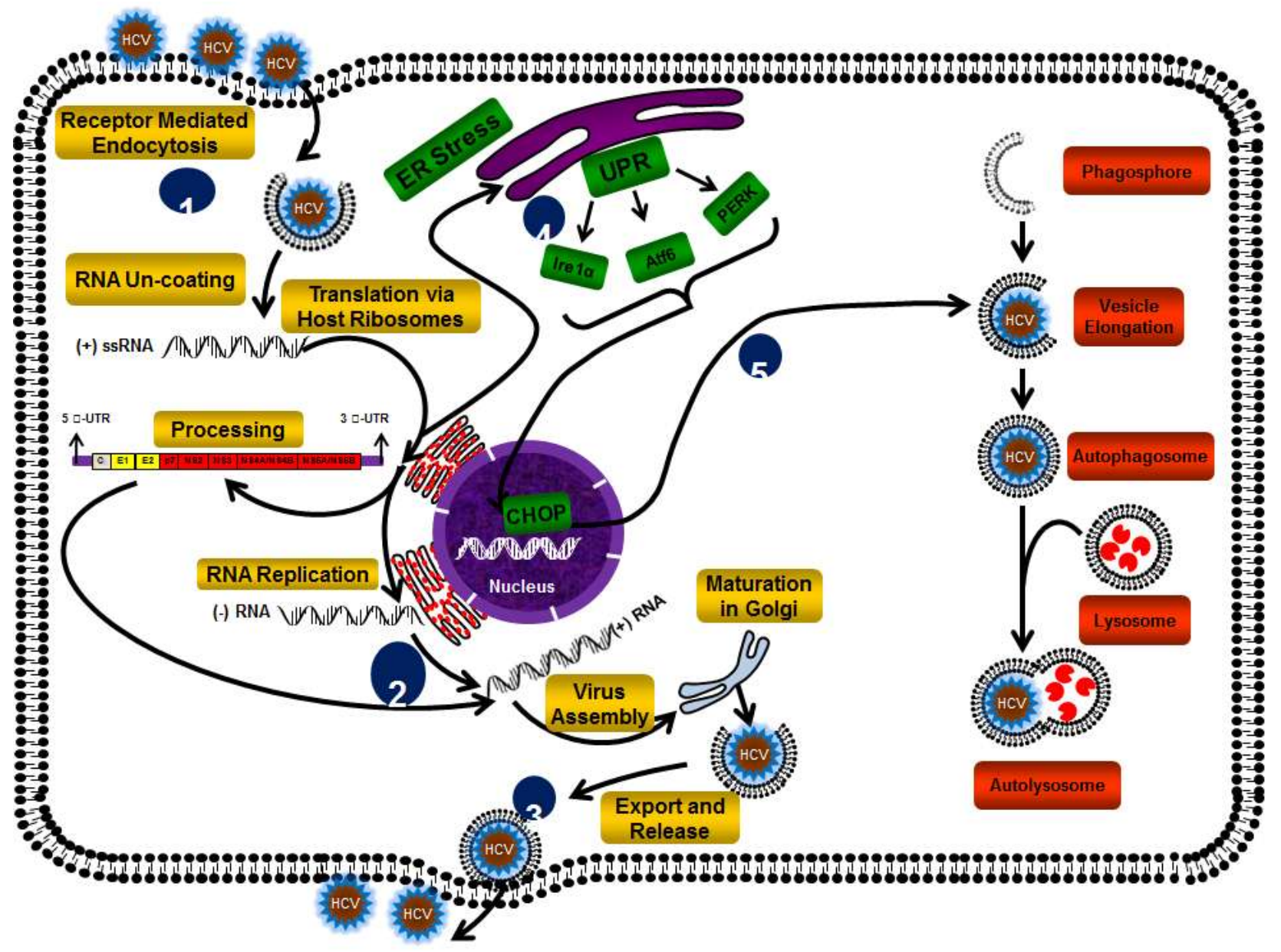

Figure 5: Diagram showing a typical HCV life cycle, activation of the Unfolded Protein Response and autophagy after HCV infection. (1) HCV enters liver cells via receptor-mediated endocytosis. (2) After RNA uncoating, the positive- strand RNA is a template for both translation (via host ribosomes) and RNA replication (via synthesis of negative- and then positive-strand RNA). (3) Following assembly of virion particles and glycoprotein maturation in the Endoplasmic reticulum and Golgi apartaus, HCV particles are transport and released from hepatocytes. (4) HCV infection results in ER stress and the accumulation and aggregation of unfolded proteins, triggering activation of PERK, ATF6 and IRE1 1 , three known ER stress receptors that promote the expression of CHOP. (5) An increase in CHOP expression activates the autophagy process via facilitating autophagosome formation.

therapeutics for at least some forms of hepatitis. HBV and HCV infections are significant worldwide health-threatening problems that cause huge healthcare budget expenditures every year in developed and developing countries. Every year, scores of $\mathrm{HBV}$ and $\mathrm{HCV}$ infected individuals enter the end-stages of the diseases, Therefore, 
developing new therapeutic approaches are a very urgent matter. Targeting the life cycle of these viruses using molecular biology approaches could yield promising effects. Since HBV and HCV specifically modulate autophagy in host cells to enhance virion production (as described previously), targeting different steps of autophagy that modulate HBV and HCV replication and life cycle opens the way for the development of novel therapeutic strategies for these diseases. Autophagy is tightly linked to other cell death pathways involving apoptosis, necrosis, and ER-stress induced cell death. Therefore, targeting autophagy to direct the infected host cells being killed by other cell death mechanism could yield another strategy to combat HBV and HCV infection.

Research and development of new anti-HBV and -HCV drugs is also hampered by the lack of good in vitro models of HBV- and HCV infection as well as lack of understanding of docking mechanisms used by these viruses to enter hepatocytes. Recent development in reprogramming (iPS-generation) as well as in regenerative medicine techniques, may soon allow overcoming those hurdles by creation of in vitro liver models.

\section{Aknowledgement}

SG is supported by Parker B Francis postdoctoral Fellowship in respiratory diseases. SR and BY Ande is supported by MHR postdoctoral fellowship. 
Table 1: Hepatitis B virus open reading frames and proteins

\begin{tabular}{|c|c|c|c|c|c|}
\hline \multirow[b]{2}{*}{$\begin{array}{l}\text { Protein } \\
\text { Name }\end{array}$} & \multirow{2}{*}{$\begin{array}{c}\text { ORF } \\
\text { Location } \\
\text { (nt) }\end{array}$} & \multicolumn{3}{|c|}{ Protein } & \multirow[b]{2}{*}{ Function } \\
\hline & & & $\mathrm{e} \mathrm{kDa}$ & $\begin{array}{c}\text { Size if } \\
\text { glycosylated }\end{array}$ & \\
\hline C & $1901-2449$ & 183 & 21.5 & $\mathrm{n} / \mathrm{a}$ & Core structural protein \\
\hline $\mathrm{E}$ & $\sim 1901-2385$ & $\sim 162$ & 16 & $n / a$ & Secreted \\
\hline$P$ & $2307-1620$ & 843 & 90 & $\mathrm{n} / \mathrm{a}$ & $\begin{array}{c}\text { Polymerase, Primer, Reverse } \\
\text { Transcriptase, RNaseH }\end{array}$ \\
\hline$S(s)$ & $155-832$ & 226 & 24 & $26-27$ & Small surface protein \\
\hline (m) & $3205-832$ & 281 & 33 & 36 & Medium surface protein \\
\hline (l) & $2848-832$ & 399 & 39 & 42 & Large surface protein \\
\hline$x$ & $1374-1835$ & 154 & 17 & $\mathrm{n} / \mathrm{a}$ & Transactivator \\
\hline
\end{tabular}

HB056 strain; GenBank \# HM011465.1 
Table 2 Hepatitis $C$ virus open reading frames and proteins

\begin{tabular}{|c|c|c|c|c|c|}
\hline \multirow{3}{*}{$\begin{array}{l}\text { Protein } \\
\text { Name }\end{array}$} & \multirow{3}{*}{$\begin{array}{c}\text { ORF } \\
\text { Location } \\
\text { (nt) }\end{array}$} & \multicolumn{3}{|c|}{ Protein } & \multirow[b]{3}{*}{ Function } \\
\hline & & \multicolumn{2}{|c|}{ Size } & \multirow{2}{*}{$\begin{array}{c}\text { Size if } \\
\text { glycosylated }\end{array}$} & \\
\hline & & a.a. & $\mathrm{kDa}$ & & \\
\hline C & $342-917^{\star}$ & 192 & 21 & $\mathrm{n} / \mathrm{a}$ & $\begin{array}{l}\text { Core (Nucleocapsid) structural } \\
\text { protein }\end{array}$ \\
\hline E1 & $918-1493$ & 192 & 21 & 33-35 & Envelope protein, Fusion domain? \\
\hline E2 & $1494-2582$ & 363 & 38 & $70-72$ & $\begin{array}{l}\text { Envelope protein, Receptor } \\
\text { binding, Fusion? }\end{array}$ \\
\hline p7 & $2583-2771$ & 63 & 7 & & Viral cation channel, Viroporin \\
\hline NS2 & $2772-3422$ & 217 & 22 & & Autocatalytic protease \\
\hline NS3 & $3423-5315$ & 631 & 69 & & Protease, NTPase/helicase \\
\hline NS4A & $5316-5477$ & 54 & 6 & & Protease cofactor \\
\hline NS4B & $5478-6260$ & 261 & 27 & & Membranous web induction \\
\hline NS5A & $6261-7604$ & 448 & $56-58$ & & RNA replication \\
\hline NS5B & $7605-9374$ & 590 & 68 & & $\begin{array}{l}\text { RNA dependent RNA polymerase } \\
\quad(\mathrm{RdRp})\end{array}$ \\
\hline
\end{tabular}

J4 clone; GenBank \# AF054247.1; 9595 nucleotides

* All proteins produced from a single ORF (nt $342-9374$ ) that is co-translationally and post-translationally cleaved by viral- and cellular-encoded proteases. Values shown represent locations within single large ORF. 


\section{Reference}

1 Gonzalez-Aseguinolaza G, Crettaz J, Ochoa L, Otano I, Aldabe R, Paneda A. Gene therapy for viral hepatitis. Expert Opin Biol Ther. 2006; 6(12):1263-78.

2 Grunhage F, Nattermann J. Viral hepatitis: human genes that limit infection. Best Pract Res Clin Gastroenterol. 2010; 24(5):709-23.

3 McHutchison JG, Bacon BR. Chronic hepatitis C: an age wave of disease burden. Am J Manag Care. 2005; 11(10 Suppl):S286-95; quiz S307-11.

4 Gutierrez-Reyes G, Gutierrez-Ruiz MC, Kershenobich D. Liver fibrosis and chronic viral hepatitis. Arch Med Res. 2007; 38(6):644-51.

5 Ait-Goughoulte M, Kanda T, Meyer K, Ryerse JS, Ray RB, Ray R. Hepatitis C virus genotype 1a growth and induction of autophagy. J Virol. 2008; 82(5):2241-9.

6 Guevin C, Manna D, Belanger C, Konan KV, Mak P, Labonte P. Autophagy protein ATG5 interacts transiently with the hepatitis C virus RNA polymerase (NS5B) early during infection. Virology. 2010; 405(1):1-7.

7 Lee YR, Lei HY, Liu MT, et al. Autophagic machinery activated by dengue virus enhances virus replication. Virology. 2008; 374(2):240-8.

8 Alavian SM, Zamiri N, Gooya MM, Tehrani A, Heydari ST, Lankarani KB. Hepatitis B vaccination of adolescents: A report on the national program in Iran. J Public Health Policy. 2010; 31(4):478-93.

9 Alavian SM, Gooya MM, Hajarizadeh B, et al. Mass Vaccination Campaign against Hepatitis B in Adolescents in Iran: Estimating Coverage using Administrative Data. Hepat Mon. 2009; 9(3):189-95. 
10 Janssen HL, van Zonneveld M, Schalm SW. Hepatitis B. N Engl J Med. 2004; 350(26):2719-20.

11 Darvish-Moghadam S, Haghdoost AA, Hoseini SH, Ramazani R, Rezazadehkermani M. Incidence of Hepatocellular Carcinoma in Southeast Iran. Hepat Mon. 2010; 10(4):270-4.

12 Nokhodian Z, Kassaian N, Ataei B, et al. Hepatitis B Markers in Isfahan, Central Iran: A Population-Based Study. Hepat Mon. 2009; 9(1):12-6.

13 Salkic NN. Intrafamilial Transmission of Hepatitis B: Experience and Lessons Learned in Bosnia and Herzegovina. Hepat Mon. 2009; 9(3):169-70.

14 Umar M, Bushra $\mathrm{H}$, Ahmad $\mathrm{M}$, et al. Hepatitis $\mathrm{C}$ in Pakistan: A Review of Avaiable Data. Hepat Mon. 2010; 10(3):205-14.

15 Khedmat H, Alavian SM, Miri SM, et al. Trends in Seroprevalence of Hepatitis B, Hepatitis C, HIV, and Syphilis Infections in Iranian Blood Donors from 2003 to 2005. Hepat Mon. 2009; 9(1):24-8.

16 Alavian SM, Gholami B, Masarrat S. Hepatitis C risk factors in Iranian volunteer blood donors: A case-control study. J Gastroenterol Hepatol. 2002; 17(10):1092-7.

17 Jalali MV, Alavian SM. Hepatitis B e Antigen-Negative chronic hepatitis B. Hepat Mon. 2006; 6(1):31-5.

18 Yeung P, Wong DK, Lai CL, Fung J, Seto WK, Yuen MF. Association of Hepatitis B Virus Pre-S Deletions with the Development of Hepatocellular Carcinoma in Chronic Hepatitis B. J Infect Dis. 2011.

19 Thomas DL, Thio CL, Martin MP, et al. Genetic variation in IL28B and spontaneous clearance of hepatitis C virus. Nature. 2009; 461(7265):798-801. 
20 Alavian SM. Are the Real HCV Infection Features in Iranian Patients the Same As What Is Expected? Hepat Mon. 2005; 5(1):3-5.

21 Thomas DL, Astemborski J, Rai RM, et al. The natural history of hepatitis C virus infection: host, viral, and environmental factors. Jama. 2000; 284(4):450-6.

22 Seeff LB. Natural history of chronic hepatitis C. Hepatology. 2002; 36(5 Suppl 1):S35-46.

23 Seeger C, Zoulim F, Mason WS. Hepadnaviruses. In: Knipe DM, Howley PM, eds. Fields Virology. Vol. 25 edn. Philadelphia: Lippincott Williams \& Wilkins, 2007: 2977-3029.

24 Zuckerman AJ. Hepatitis viruses. Encyclopedia of Life Sciences: Elsevier, 2006.

25 Jilbert AR, Reaiche GY, Clouston A, Mason WS. Hepatitis B virus. Encyclopedia of Life Sciences: John Wiley \& Sons, Ltd: Chichester, 2011.

26 Tang $\mathrm{H}$, Da $\mathrm{L}$, Mao $\mathrm{Y}$, et al. Hepatitis $\mathrm{B}$ virus $\mathrm{X}$ protein sensitizes cells to starvation-induced autophagy via up-regulation of beclin 1 expression. Hepatology. $2009 ; 49(1): 60-71$.

27 Sir D, Tian Y, Chen WL, Ann DK, Yen TS, Ou JH. The early autophagic pathway is activated by hepatitis B virus and required for viral DNA replication. Proc Natl Acad Sci U S A. 2010; 107(9):4383-8.

28 Li J, Liu Y, Wang Z, et al. Subversion of Cellular Autophagy Machinery by Hepatitis B Virus for Viral Envelopment. Journal of Virology. 2011.

29 Klein KC, Dellos SR, Lingappa JR. Identification of residues in the hepatitis C virus core protein that are critical for capsid assembly in a cell-free system (vol 79, pg 6814, 2005). Journal of Virology. 2005; 79(15):10098-. 
30 Lemon SM, Walker C, Alter MJ, Yi MK. Hepatitis C Virus. In: Knipe DM, Howley PM, eds. Fields Virology. Vol. 15 edn. Philadelphia: Lippincott Williams \& Wilkins, 2007: 1253-304.

31 Harris M. Hepatitis C virus. Encyclopedia of Life Sciences: John Wiley \& Sons, Ltd: Chichester, 2007.

32 Sir D, Chen WL, Choi J, Wakita T, Yen TS, Ou JH. Induction of incomplete autophagic response by hepatitis $\mathrm{C}$ virus via the unfolded protein response. Hepatology. 2008; 48(4):1054-61.

33 Asselah T, Bieche I, Mansouri A, et al. In vivo hepatic endoplasmic reticulum stress in patients with chronic hepatitis C. J Pathol. 2010; 221(3):264-74.

34 Ke PY, Chen SS. Activation of the unfolded protein response and autophagy after hepatitis $\mathrm{C}$ virus infection suppresses innate antiviral immunity in vitro. J Clin Invest. 2011; 121(1):37-56.

35 Ravikumar B, Sarkar S, Davies JE, et al. Regulation of mammalian autophagy in physiology and pathophysiology. Physiol Rev. 2010; 90(4):1383-435.

36 Rabinowitz JD, White E. Autophagy and metabolism. Science. 2010; 330(6009):1344-8.

37 Ghavami S, Eshragi M, Ande SR, et al. S100A8/A9 induces autophagy and apoptosis via ROS-mediated cross-talk between mitochondria and lysosomes that involves BNIP3. Cell Res. 2010; 20(3):314-31.

38 Ghavami S, Mutawe MM, Sharma $\mathrm{P}$, et al. Mevalonate cascade regulation of airway mesenchymal cell autophagy and apoptosis: a dual role for p53. PLoS One. 2011; 6(1):e16523. 
39 Levine B, Mizushima N, Virgin HW. Autophagy in immunity and inflammation. Nature. 2011; 469(7330):323-35.

40 Youle RJ, Narendra DP. Mechanisms of mitophagy. Nat Rev Mol Cell Biol. 2011; 12(1):9-14

41 Mijaljica D, Prescott M, Devenish RJ. Mitophagy and mitoptosis in disease processes. Methods Mol Biol. 2010; 648:93-106.

42 Macintosh GC, Bassham DC. The connection between ribophagy, autophagy and ribosomal RNA decay. Autophagy. 2011; 7(6).

43 Weidberg H, Shvets E, Elazar Z. Lipophagy: selective catabolism designed for lipids. Dev Cell. 2009; 16(5):628-30.

44 Alexander DE, Leib DA. Xenophagy in herpes simplex virus replication and pathogenesis. Autophagy. 2008; 4(1):101-3.

45 Ghavami S, Asoodeh A, Klonisch T, et al. Brevinin-2R(1) semi-selectively kills cancer cells by a distinct mechanism, which involves the lysosomal-mitochondrial death pathway. J Cell Mol Med. 2008; 12(3):1005-22.

46 Kang R, Livesey KM, Zeh HJ, 3rd, Lotze MT, Tang D. HMGB1 as an autophagy sensor in oxidative stress. Autophagy. 2011; 7(8).

47 Rautou PE, Mansouri A, Lebrec D, Durand F, Valla D, Moreau R. Autophagy in liver diseases. J Hepatol. 2010; 53(6):1123-34.

48 Wu S, Sun J. Vitamin D, vitamin D receptor, and macroautophagy in inflammation and infection. Discov Med. 2011; 11(59):325-35.

49 Shen S, Kepp O, Michaud M, et al. Association and dissociation of autophagy, apoptosis and necrosis by systematic chemical study. Oncogene. 2011. 
50 Fan W, Nassiri A, Zhong Q. Autophagosome targeting and membrane curvature sensing by Barkor/Atg14(L). Proc Natl Acad Sci U S A. 2011; 108(19):7769-74.

51 Shang L, Wang X. AMPK and mTOR coordinate the regulation of Ulk1 and mammalian autophagy initiation. Autophagy. 2011; 7(8).

52 Kang R, Zeh HJ, Lotze MT, Tang D. The Beclin 1 network regulates autophagy and apoptosis. Cell Death Differ. 2011; 18(4):571-80.

53 Cherra SJ, 3rd, Kulich SM, Uechi G, et al. Regulation of the autophagy protein LC3 by phosphorylation. J Cell Biol. 2010; 190(4):533-9.

54 Tanida I, Ueno T, Kominami E. LC3 and Autophagy. Methods Mol Biol. 2008; 445:77-88.

55 Ueno T, Sato W, Horie $\mathrm{Y}$, et al. Loss of Pten, a tumor suppressor, causes the strong inhibition of autophagy without affecting LC3 lipidation. Autophagy. 2008; 4(5):692-700 .

56 Fortunato $\mathrm{F}$, Burgers $\mathrm{H}$, Bergmann $\mathrm{F}$, et al. Impaired autolysosome formation correlates with Lamp-2 depletion: role of apoptosis, autophagy, and necrosis in pancreatitis. Gastroenterology. 2009; 137(1):350-60, 60 e1-5.

57 McFarlane S, Aitken J, Sutherland JS, Nicholl MJ, Preston VG, Preston CM. Early induction of autophagy in human fibroblasts after infection with human cytomegalovirus or herpes simplex virus 1. Journal of Virology. 2011; 85(9):4212-21.

58 Kumar SH, Rangarajan A. Simian virus 40 small T antigen activates AMPK and triggers autophagy to protect cancer cells from nutrient deprivation. $J$ Virol. 2009; 83(17):8565-74. 
59 Zhou Z, Jiang X, Liu D, et al. Autophagy is involved in influenza A virus replication. Autophagy. 2009; 5(3):321-8.

60 Jackson WT, Giddings TH, Jr., Taylor MP, et al. Subversion of cellular autophagosomal machinery by RNA viruses. PLOS Biol. 2005; 3(5):e156.

61 Taylor MP, Kirkegaard K. Modification of cellular autophagy protein LC3 by poliovirus. J Virol. 2007; 81(22):12543-53.

62 Wong J, Zhang J, Si X, et al. Autophagosome supports coxsackievirus B3 replication in host cells. J Virol. 2008; 82(18):9143-53.

63 Zhang Y, Li Z, Xinna G, Xin G, Yang H. Autophagy promotes the replication of encephalomyocarditis virus in host cells. Autophagy. 2011; 7(7).

64 Dreux M, Gastaminza P, Wieland SF, Chisari FV. The autophagy machinery is required to initiate hepatitis C virus replication. Proc Natl Acad Sci U S A. 2009; 106(33):14046-51.

65 Ke PY, Chen SS. Autophagy: A novel guardian of HCV against innate immune response. Autophagy. 2011; 7(5):533-5.

66 Mizui T, Yamashina S, Tanida I, et al. Inhibition of hepatitis C virus replication by chloroquine targeting virus-associated autophagy. J Gastroenterol. 2010; 45(2):195203.

67 Shrivastava S, Raychoudhuri A, Steele R, Ray R, Ray RB. Knockdown of autophagy enhances the innate immune response in hepatitis $\mathrm{C}$ virus-infected hepatocytes. Hepatology. 2011; 53(2):406-14. 